\title{
EFFECTS OF CONVENTIONAL MECHANICAL VENTILATION PERFORMED BY TWO NEONATAL VENTILATORS ON THE LUNG FUNCTIONS OF RABBITS WITH MECONIUM-INDUCED ACUTE LUNG INJURY
}

\author{
MOKRA D ${ }^{1}$, MIKOLKA P ${ }^{1}$, KOSUTOVA P ${ }^{1}$, KOLOMAZNIK M ${ }^{1}$, JURCEK $\mathrm{M}^{2}$, ISTONA P2, \\ MATASOVA $\mathrm{K}^{3}$, ZIBOLEN M${ }^{3}$, CALKOVSKA A ${ }^{1}$
}

${ }^{1}$ Comenius University, Jessenius Faculty of Medicine in Martin, Biomedical Center and Department of Physiology, Martin, Slovakia; ${ }^{2}$ Chirana Stara Tura a.s., Slovakia; ${ }^{3}$ Comenius University, Jessenius Faculty of Medicine and University Hospital, Neonatology Clinic, Martin, Slovakia

\begin{abstract}
Severe meconium aspiration syndrome (MAS) in the neonates often requires a ventilatory support. As a method of choice, a conventional mechanical ventilation with small tidal volumes $\left(\mathrm{V}_{\mathrm{T}}<6 \mathrm{ml} / \mathrm{kg}\right)$ and appropriate ventilatory pressures is used. The purpose of this study was to assess the short-term effects of the small-volume CMV performed by two neonatal ventilators: Aura V (Chirana Stara Tura a.s., Slovakia) and SLE5000 (SLE Ltd., UK) on the lung functions of rabbits with experimentally-induced MAS and to estimate whether the newly developed neonatal version of the ventilator Aura V is suitable for ventilation of the animals with MAS.

In the young rabbits, a model of MAS was induced by an intratracheal instillation of a suspension of neonatal meconium (4 ml $/ \mathrm{kg}, 25 \mathrm{mg} / \mathrm{ml})$. After creating the model of MAS, the animals were ventilated with small-volume CMV (frequency $50 / \mathrm{min}, \mathrm{V}_{\mathrm{T}}<6 \mathrm{ml} / \mathrm{kg}$, inspiration time $50 \%$, fraction of inspired oxygen 1.0, positive end-expiratory pressure $0.5 \mathrm{kPa}$, mean airway pressure $1.1 \mathrm{kPa}$ ) performed by ventilator Aura V (Aura group, n=7) or ventilator SLE5000 (SLE group, $n=7$ ) for additional 4 hours. One group of animals served as healthy non-ventilated controls ( $n=6)$. Blood gases, oxygenation indexes, ventilatory pressures, lung compliance, oxygen saturation and total and differential white blood cell (WBC) count were regularly determined. After euthanizing the animals, a left lung was saline-lavaged and total and differential counts of cells in the bronchoalveolar lavage (BAL) fluid were determined. A right lung was used for estimation of lung edema formation (expressed as a wet/dry weight ratio) and for analysis of concentrations of pro-inflammatory cytokines (IL-1 $\beta$, IL-8, TNF ). The cytokines were measured also in the blood plasma taken at the end of experiment.

Meconium instillation seriously worsened the gas exchange and induced inflammation and lung edema formation. In the Aura group, slightly lower concentrations of cytokines were found and better gas exchange early after creating the MAS model was observed. However, there were no significant differences in the respiratory parameters between the ventilated groups at the end of experiment $(\mathrm{P}>0.05)$.

Concluding, the newly developed neonatal version of the ventilator Aura V was found to be fully comparable to widely used neonatal ventilator SLE5000. Results provided by Aura V in CMV ventilation of rabbits with meconium-induced acute lung injury suggest its great potential also for future clinical use, i.e. for ventilation of the neonates with MAS.
\end{abstract}

Key words: Conventional mechanical ventilation, meconium aspiration, lung injury, rabbit.

\section{INTRODUCTION}

Meconium aspiration syndrome (MAS) represents a respiratory distress in an infant born through the meconium-stained amniotic fluid (MSAF) with characteristic radiological changes, which symptoms cannot be otherwise explained. Meconium (or first faeces of the newborn) can be inhaled into the airways during intrauterine gasping or during the first few breaths after the labor. Although MSAF is present in 8-20 \% of all deliveries and its occurance increases with a gestation age, only about 2-9 \% of infants born through MSAF develop MAS. The clinical manifestations include respiratory distress, tachypnea, cyanosis, end-expiratory grunting, alar flaring, retractions of intercostal spaces, barrel chest (increased antero-posterior diameter) due to

Address for correspondence:

Daniela Mokra, MD., PhD., Biomedical Center Martin and Department of Physiology, Jessenius Faculty of Medicine in Martin, Comenius University 03601 Martin, Mala Hora Str. N. 4C, Slovakia

Phone: +421 43 2633454; mobil: +421905 733681; email: mokra@jfmed.uniba.sk 
a presence of air trapping, and rales and rhonchi in auscultation investigation. Mortality rate for MAS is around 2.5-5 \% $(1,2)$.

The pathophysiology of MAS is complex. An early phase after meconium aspiration is characterized by a large airway obstruction, an increase in lung resistance and functional residual capacity, a decrease in lung compliance, and by hypoxemia, hypercapnia and acidosis. In a later phase, meconium spreads distally with breathing and obstructs medium and small airways. Due to action of meconium components (such as phospholipase A2, free fatty acids, bile acids and salts, cholesterol, bilirubin etc.), inflammatory and vasoconstriction changes and collapse of the airways and alveoli and lung edema can be detected as a result of „chemical“ pneumonia and dysfunction of pulmonary surfactant $(2,3)$.

For treatment of MAS, a supplemental oxygen administration is a mainstay and in less severe cases it could be the only therapy needed (4). Approximately 10-20\% of infants requiring a respiratory support because of MAS are treated with continuous positive airway pressure (CPAP) alone (4), however, its use in MAS because of significant airway obstruction and risk of pneumothorax has been discussed. About one-third of all infants with diagnosis of MAS need intubation and mechanical ventilation, whereas indications for intubation of infants with MAS include high oxygen requirement (fraction of inspired oxygen, $\mathrm{FiO}_{2}$ 0.8), respiratory acidosis with arterial $\mathrm{pH}$ persistently less than 7.25 , pulmonary hypertension, and circulatory compromise with poor systemic blood pressure and perfusion (5).

For the use of conventional mechanical ventilation (CMV) in infants with MAS, some basic recommendations have been considered: a) use of synchronized mode of ventilation, if possible, b) appropriate values of positive end-expiratory pressure (PEEP) of 0.4-0.7 kPa to overcome atelectasis whilst avoiding overdistension, c) peak inspiratory pressure (PIP) set at or near 30 $\mathrm{cm} \mathrm{H}_{2} \mathrm{O}(3 \mathrm{kPa})$ to reach a target value of tidal volume $\left(\mathrm{V}_{\mathrm{T}}\right)$ of $5-6 \mathrm{ml} / \mathrm{kg}$ b.w. (or a peak pressure limit of $3 \mathrm{kPa}$ in a „volume-guarantee mode“), d) inspiratory time (Ti) around $0.5 \mathrm{~s}$ because of longer time constants in the term infants, e) respiratory rate (usually $<50 / \mathrm{min}$ ) to produce sufficient $\mathrm{CO}_{2}$ clearance $(5,6)$. This lung-protective mode of ventilation is expected to have less adverse effects on the lung tissue and on the pulmonary circulation and therefore has become a "gold standard" of ventilation therapy in the newborns with MAS.

There are many neonatal ventilators from a lot of producers which are able to supply a sufficient gas exchange in the neonates suffering from MAS. However, there is actually only one CMV ventilator of a Slovak producer. Chirana Stara Tura a.s. is a Slovak company which has traditionally concerned on the production of a medical equipment. Nowadays, they have returned back to the idea of development and production of mechanical ventilators, which had been several decades ago realized in co-operation with Konstrukta Trencin. A few years ago, an efficacy of a prototype of the neonatal version of the ventilator Aura V by Chirana was evaluated in our laboratory (7). According to our pilot results from in vivo testing and according to measurements realized in in vitro conditions, a number of technical changes has been made. Actually, a newly developed neonatal version of ventilator Aura $\mathrm{V}$ with improved technical parameters has an ambition to be a valuable alternative to neonatal ventilators of the producers from abroad.

Therefore, the purpose of this study was to evaluate the short-term effects of CMV provided by two neonatal ventilators: Aura V produced by Chirana Stara Tura and SLE5000 produced by SLE Ltd. The effectiveness of both ventilators was determined on young rabbits with experimentally-induced MAS where the changes of the lung functions including gas exchange were measured regularly during the experiment and markers of inflammation and lung injury in the lung tissue and blood plasma were detected after finishing the experiment.

\section{METHODS}

\section{Meconium}

First-pass meconium was collected from diapers of healthy term neonates (in co-operation with Neonatology Clinics, Jessenius Faculty of Medicine and University Hospital in Martin), 
was pooled, lyophilized and stored at $-20^{\circ} \mathrm{C}$. Before use, meconium was suspended in a normal saline $\left(0.9 \% \mathrm{NaCl}, 37^{\circ} \mathrm{C}\right)$ at a concentration of $25 \mathrm{mg} / \mathrm{ml}$.

\section{General Design of Experiments}

Experimental protocols were performed in accordance with the ethical guidelines and authorized by the local Ethics Committee of Jessenius Faculty of Medicine and by the National Veterinary Board.

In the study, young (approximately 8-week-old) New Zealand white rabbits of both genders and a mean body weight (b.w.) \pm standard deviation (SD) of $2.0 \pm 0.3 \mathrm{~kg}$ were used. Animals were anesthetized with intramuscular tiletamine + zolazepam $(15 \mathrm{mg} / \mathrm{kg}$ b.w.; Zoletil, Virbac, France) and xylazine (5 mg/kg b.w.; Xylariem, Riemser, Germany), followed by an intravenous tiletamine + zolazepam (10 mg/kg b.w./h; Zoletil, Virbac, France). A tracheotomy was performed and an endotracheal tube (internal diameter of $3.5 \mathrm{~mm}$ ) was inserted. Thin polypropylene catheters were inserted into the femoral artery and right atrium for sampling the arterial and mixed venous blood, and into the femoral vein to administer anesthetics and solutions. Six animals (Contr group) were euthanized at this moment and they served as healthy non-ventilated controls for analyses of markers of inflammation. Other animals were paralyzed with pipecuronium bromide (0.3 mg/kg b.w./30 min; Arduan, Gedeon Richter, Hungary) and ventilated with ventilator Aura V (Chirana Stara Tura a.s., Slovakia; Aura group, n=7) or ventilator SLE5000 (SLE Ltd., UK; SLE group, $\mathrm{n}=7$ ) with the following settings: frequency (f.) of $40 / \mathrm{min}, \mathrm{FiO}_{2}$ of 0.5 , Ti of $50 \%$, PEEP of $0.5 \mathrm{kPa}$, mean airway pressure (MAP) of $0.7-0.8 \mathrm{kPa}$, and $\mathrm{V}_{\mathrm{T}}<6 \mathrm{ml} / \mathrm{kg} \mathrm{b}$.w. After $15 \mathrm{~min}$. of stabilization, ventilatory parameters and lung compliance were recorded and blood samples were taken for analysis of blood gases by a blood gas analyzer (RapidLab ${ }^{348}$, Siemens, Germany).

Model of MAS was induced by an intratracheal administration of $4 \mathrm{ml} / \mathrm{kg}$ b.w. of meconium suspension $(25 \mathrm{mg} / \mathrm{ml})$, which was instilled into the tracheal tube in the semi-upright right and left lateral positions of the animal to provide a homogenous distribution of meconium. Then, the ventilatory settings were changed to supply an appropriate gas exchange, i.e., $\mathrm{FiO}_{2}$ was increased to 1.0 and $\mathrm{f}$. to $50 / \mathrm{min}$. Within $30 \mathrm{~min}$ after meconium instillation, the respiratory distress characterized by a decrease of lung compliance of more than $30 \%$ compared to initial values and a significant decrease in arterial partial pressure of oxygen $\left(\mathrm{PaO}_{2}\right)$ has developed. Blood samples were taken again and blood gases, respiratory parameters and indexes were measured and calculated. From the moment when the criteria for the model of MAS were fulfilled, animals were ventilated with the following settings: f. 50/min, $\mathrm{V}_{\mathrm{T}}<6 \mathrm{ml} / \mathrm{kg}, \mathrm{Ti} 50 \%, \mathrm{FiO}_{2}$ 1.0, PEEP of $0.5 \mathrm{kPa}$, MAP of $1.1 \mathrm{kPa}$ with the same ventilator (Aura $\mathrm{V}$ in the Aura group and SLE5000 in the SLE group) for additional $4 \mathrm{~h}$. During the course of experiment, values of PIP and MAP might slightly change according to the actual value of $\mathrm{PaCO}_{2}$, which we tried to keep in the recommended range of $5.3-6.7 \mathrm{kPa}(40-50 \mathrm{~mm} \mathrm{Hg})$. To reduce acidosis, animals were intravenously given an infusion of $0.45 \%$ saline and $5 \%$ glucose $(2 \mathrm{ml} / \mathrm{h})$ and a bolus of $4 \%$ sodium bicarbonate when arterial $\mathrm{pH}$ decreased to value $<7.2$. The blood gases and respiratory parameters were measured at 30 min., 1, 2, 3, and $4 \mathrm{~h}$ after induction of MAS model. At the end of experiment, animals were overdosed by anesthetics.

\section{Measurement and calculation of blood gases, respiratory parameters and indexes}

Partial pressures of blood gases $\left(\mathrm{PaO}_{2}, \mathrm{PaCO}_{2}\right)$ and $\mathrm{pH}$ in the arterial and mixed venous blood and arterial oxygen saturation of hemoglobin $\left(\right.$ Sat. $\mathrm{O}_{2}$ ) as well as other parameters of acid-base balance were measured by the blood analyzer (Rapidlab ${ }^{348}$, Siemens, Germany).

During CMV ventilation, basic respiratory parameters, such as frequency, ventilatory pressures (PIP, PEEP, MAP), $\mathrm{V}_{\mathrm{T}}, \mathrm{FiO}_{2}$, minute ventilation, $\mathrm{Ti}$, static lung compliance etc. have been automatically measured by in-built sensors and softwares and displayed directly on the screens of the ventilators Aura V and SLE5000.

Two clinically important indexes of oxygenation were also determined. Oxygenation index (OI) was calculated as: $\mathrm{OI}=[\mathrm{MAP}$ (in $\mathrm{kPa}) \times \mathrm{FiO}_{2}$ (in \%) $] / \mathrm{PaO}_{2}$ (in $\mathrm{kPa}$ ). $\mathrm{PF}$ ratio was calculated as: $\mathrm{PF}$ ratio $=\left[\mathrm{PaO}_{2}\right.$ (in $\mathrm{mmHg}$ ) $\left.\times 100\right] / \mathrm{FiO}_{2}$ (in \%). 


\section{Counting of white blood cells (WBC) in the blood}

Samples of the arterial blood for WBC counting were taken before creating of MAS model and at $4 \mathrm{~h}$ after induction of MAS model. Total WBC count was determined microscopically in a counting chamber after staining by Türck. Differential WBC count was estimated microscopically after staining by May-Grünwald/Giemsa-Romanowski.

\section{Counting of cells in the BAL fluid}

After euthanizing the animal, lung and trachea were excised. Left lung was lavaged 3-times by saline $\left(0.9 \% \mathrm{NaCl}, 37^{\circ} \mathrm{C}\right)$ at a dose of $10 \mathrm{ml} / \mathrm{kg}$ b.w. Total number of cells in the bronchoalveolar lavage (BAL) fluid was determined using an automated cell counter Countess (Invitrogen, Thermo Scientific, USA). Then, the BAL fluid was centrifuged at $1500 \mathrm{rpm}$ for $10 \mathrm{~min}$. Differential count of cells in the sediment of BAL fluid was estimated microscopically after staining by May-Grünwald/Giemsa-Romanowski.

\section{Lung edema formation (wet/dry lung weight ratio)}

Strips of the right lung tissue were cut and a wet weight was measured. Then, the strips were dried at $60^{\circ} \mathrm{C}$ for $24 \mathrm{~h}$, a dry weight was measured and a wet-dry ratio was calculated.

\section{Biochemical analyses of pro-inflammatory cytokines in the plasma and the lung tissue}

Preparation of the blood plasma. Samples of the arterial blood taken at the end of experiment were centrifuged (3000 $\mathrm{rpm}$ for $15 \mathrm{~min}, 4^{\circ} \mathrm{C}$ ) and plasma was stored at $-70{ }^{\circ} \mathrm{C}$ until the analyses were performed.

Preparation of the lung tissue homogenate. Strips of the right lung lobe were homogenized (5-times for $25 \mathrm{~s}, 1200 \mathrm{rpm}$ ) in an ice-cold phosphate buffer (pH 7.4). Homogenates were then 3-times freezed and centrifuged (12000 rpm for $\left.15 \mathrm{~min}, 4^{\circ} \mathrm{C}\right)$. The final supernatants were stored at $-70{ }^{\circ} \mathrm{C}$ until the analyses were performed. A protein concentration in the lung homogenates was determined according to the methods described by Lowry et al. (8), using a bovine serum albumin as a standard.

Measurement of the cytokine concentrations by an enzyme-linked immunosorbent assay (ELISA). Concentrations of pro-inflammatory cytokines [interleukin (IL)-1 $\beta$, IL-8, and tumor necrosis factor (TNF) $\alpha$ ] in the blood plasma and in the lung tissue homogenates were detected using commercially available rabbit-specific ELISA kits (USCN Life Science Inc., China) according to the manufacturer's instructions. Results were analyzed spectrophotometrically at $450 \mathrm{~nm}$ using an ELISA microplate reader and expressed in $\mathrm{pg} / \mathrm{ml}$.

\section{Statistics}

For analysis of data, statistical package SYSTAT for Windows was used. For comparisons in the respiratory parameters between two ventilated groups (Aura and SLE), the differences were analyzed by Kruskal-Wallis test. For comparisons among all three groups (Contr, Aura and SLE), one-way ANOVA test with post-hoc LSD test was used. Within-group differences were evaluated by Wilcoxon test. A value of $\mathrm{P}<0.05$ was considered statistically significant. Data are expressed as means \pm SEM.

\section{RESULTS}

The body weights of animals and values of the parameters before and 30 min after induction of the MAS model were comparable between the groups (all P>0.05).

\section{Blood gases, respiratory parameters and indexes}

Intratracheal instillation of meconium caused within $30 \mathrm{~min}$ a serious respiratory distress characterized by a decreased lung compliance of $47 \%$ in the Aura group and of $44 \%$ in the SLE group compared to the initial values. The decrease in compliance was accompanied with a dec- 
rease in $\mathrm{PaO}_{2}$ to $43 \%$ of the initial value in the Aura group and to $37 \%$ of the initial value in the SLE group. Hand in hand with changes in $\mathrm{PaO}_{2}$, we could observe worsening in both indexes of oxygenation, in $\mathrm{OI}$ and $\mathrm{PF}$ ratio (all $\mathrm{P}<0.05$ for comparisons of values after induction of MAS model „After MAS“ vs. initial values „Before MAS“, Tab. 1).

Table 1. Gas exchange and respiratory parameters in the animals ventilated with ventilator Aura V (Aura group) and ventilated with ventilator SLE5000 (SLE group) before meconium instillation (Before MAS) and 30 min after meconium instillation (After MAS) and at 1 and $4 \mathrm{~h}$ of ventilation therapy (Th).

\begin{tabular}{|c|c|c|c|c|}
\hline & Before MAS & After MAS & $1 \mathrm{~h} \mathrm{Th}$. & $4 \mathrm{~h}$ Th. \\
\hline $\begin{array}{l}\text { MAP: Aura } \\
\text { MAP: SLE }\end{array}$ & $\begin{array}{l}0.75 \pm 0.02 \\
0.74 \pm 0.03\end{array}$ & $\begin{array}{l}1.10 \pm 0.04^{\&} \\
1.09 \pm 0.03^{\&}\end{array}$ & $\begin{array}{l}1.12 \pm 0.03 \\
1.10 \pm 0.03\end{array}$ & $\begin{array}{l}1.12 \pm 0.04 \\
1.09 \pm 0.03\end{array}$ \\
\hline $\begin{array}{l}\text { Cst: Aura } \\
\text { Cst: SLE }\end{array}$ & $\begin{array}{l}0.017 \pm 0.001 \\
0.016 \pm 0.001\end{array}$ & $\begin{array}{l}0.009 \pm 0.001^{\&} \\
0.009 \pm 0.001^{\&}\end{array}$ & $\begin{array}{l}0.010 \pm 0.001 \\
0.008 \pm 0.001\end{array}$ & $\begin{array}{l}0.009 \pm 0.001 \\
0.009 \pm 0.001\end{array}$ \\
\hline $\begin{array}{l}\mathrm{PaO}_{2}: \text { Aura } \\
\mathrm{PaO}_{2}: \text { SLE }\end{array}$ & $\begin{array}{l}34.25 \pm 1.36 \\
35.36 \pm 1.78\end{array}$ & $\begin{array}{c}14.57 \pm 2.64^{\&} \\
12.9 \pm 1.84^{\&}\end{array}$ & $\begin{array}{l}17.10 \pm 2.36 \\
11.83 \pm 1.32^{\#}\end{array}$ & $\begin{array}{l}12.37 \pm 1.00 \\
10.93 \pm 1.25\end{array}$ \\
\hline $\begin{array}{l}\text { PF ratio: Aura } \\
\text { PF ratio: SLE }\end{array}$ & $\begin{array}{l}513.8 \pm 20.4 \\
518.5 \pm 28.3\end{array}$ & $\begin{array}{l}109.3 \pm 19.8^{\&} \\
100.9 \pm 15.5^{\&}\end{array}$ & $\begin{array}{c}128.3 \pm 17.7 \\
91.8 \pm 11.1\end{array}$ & $\begin{array}{c}92.8 \pm 7.5 \\
85.2 \pm 10.4\end{array}$ \\
\hline $\begin{array}{l}\text { OI: Aura } \\
\text { OI: SLE }\end{array}$ & $\begin{array}{l}1.1 \pm 0.1 \\
1.1 \pm 0.1\end{array}$ & $\begin{array}{l}8.7 \pm 1.3^{8} \\
8.8 \pm 1.1^{\&}\end{array}$ & $\begin{array}{l}7.2 \pm 1.1 \\
9.6 \pm 1.1\end{array}$ & $\begin{array}{c}9.5 \pm 0.9 \\
10.0 \pm 0.9\end{array}$ \\
\hline $\begin{array}{l}\text { Sat. } \mathrm{O}_{2}: \text { Aura } \\
\text { Sat. } \mathrm{O}_{2} \text { : SLE }\end{array}$ & $\begin{array}{l}99.7 \pm 0.0 \\
99.5 \pm 0.1\end{array}$ & $\begin{array}{l}95.2 \pm 1.5^{\&} \\
93.1 \pm 1.1^{\&}\end{array}$ & $\begin{array}{c}97.1 \pm 0.9 \\
92.7 \pm 1.3^{\#}\end{array}$ & $\begin{array}{l}93.0 \pm 1.2 \\
92.5 \pm 1.4\end{array}$ \\
\hline $\begin{array}{l}\mathrm{PaCO}_{2}: \text { Aura } \\
\mathrm{PaCO}_{2}: \mathrm{SLE}\end{array}$ & $\begin{array}{l}3.95 \pm 0.17 \\
4.19 \pm 0.27\end{array}$ & $\begin{array}{l}6.62 \pm 0.40^{\&} \\
7.16 \pm 0.34^{\&}\end{array}$ & $\begin{array}{c}5.32 \pm 0.35 \\
6.73 \pm 0.23^{\#}\end{array}$ & $\begin{array}{l}5.41 \pm 0.40 \\
5.61 \pm 0.48\end{array}$ \\
\hline $\begin{array}{l}\mathrm{pH}_{\mathrm{a}}: \text { Aura } \\
\mathrm{pH}_{\mathrm{a}}: \text { SLE }\end{array}$ & $\begin{array}{l}7.53 \pm 0.03 \\
7.47 \pm 0.02\end{array}$ & $\begin{array}{l}7.22 \pm 0.03^{\&} \\
7.20 \pm 0.03^{\&}\end{array}$ & $\begin{array}{c}7.22 \pm 0.01 \\
7.16 \pm 0.02^{\#}\end{array}$ & $\begin{array}{l}7.13 \pm 0.02 \\
7.14 \pm 0.02\end{array}$ \\
\hline
\end{tabular}

For between-group comparisons: ${ }^{\#} \mathrm{P}<0.05$ for Aura vs. SLE groups at the individual time points. For within-group comparisons: values „After MAS“ vs. values „Before MAS“: ${ }^{\circledR} \mathrm{P}<0.05$. Data are expressed as means \pm SEM.

The values of compliance and oxygenation remained deteriorated till the end of experiment in both ventilated groups with MAS what resulted in a higher need for ventilation as demonstrated by increased values of MAP after elicitation of MAS model vs. initial values $(\mathrm{P}<0.05$ for „After MAS“ vs. „Before MAS“). At $1 \mathrm{~h}$ of the ventilation therapy, a slightly better gas exchange was observed in the Aura group vs. SLE group (for $\mathrm{PaO}_{2} \mathrm{P}=0.046$, for $\mathrm{PaCO}_{2} \mathrm{P}=0.015$, for $\mathrm{pH}$ $\mathrm{P}=0.032$, for Sat. $\mathrm{O}_{2} \mathrm{P}=0.026$, and for $\mathrm{PF}$ ratio $\mathrm{P}=0.078$ ). However, at the end of observation (i.e. $4 \mathrm{~h}$ from elicitation of MAS model) the values of respiratory parameters were fully comparable between the groups (P>0.05, Tab. 1).

Instillation of meconium and oxygen ventilation caused a higher accumulation of fluid in the lung tissue as expressed by an increased wet-dry lung weight ratio compared to healthy nonventilated controls ( $\mathrm{P}<0.001$ for both Aura and SLE groups vs. Contr group, Tab. 2).

In both ventilated MAS-instilled groups, an increased transmigration of cells into the lungs was found compared to controls ( $\mathrm{P}<0.01$ for Aura vs. Contr and $\mathrm{P}<0.05$ for SLE vs. Contr, Tab. 2). The increase in total number of cells in BAL was related to an increased migration of polymorphonuclears, particularly neutrophils $(\mathrm{P}<0.001$ for both Aura and SLE groups vs. Contr, Tab. 2). This process was accompanied with their increase in the peripheral blood ( $\mathrm{P}<0.001$ for both Aura and SLE groups vs. Contr, Tab. 2), as well. There were no significant differences in the percentages of WBC between Aura vs. SLE groups, as 
Table 2. Markers of inflammation and lung injury in the healthy non-ventilated controls (Contr group) and in the animals with MAS ventilated with ventilator Aura V (Aura group) or ventilator SLE5000 (SLE group).

\begin{tabular}{|lccc|}
\hline & Contr group & Aura group & SLE group \\
\hline Wet-dry lung weight ratio & $4.7 \pm 0.2$ & $6.7 \pm 0.2^{* * *}$ & $6.5 \pm 0.3^{* * *}$ \\
\hline Total cells in BAL (x 10 $/ \mathrm{ml}$ ) & $105 \pm 18$ & $732 \pm 105^{* *}$ & $490 \pm 159^{*}$ \\
Monocytes/macrophages in BAL (\%) & $97.1 \pm 1.0$ & $83.0 \pm 1.8^{* * *}$ & $84.9 \pm 1.9^{* * *}$ \\
Neutrophils in BAL (\%) & $2.4 \pm 0.9$ & $15.8 \pm 1.6^{* * *}$ & $14.3 \pm 1.9^{* * *}$ \\
Eosinophils in BAL (\%) & $0.5 \pm 0.1$ & $1.2 \pm 0.2^{*}$ & $0.8 \pm 0.2$ \\
\hline Total and differential WBC count: Before MAS: & & & \\
Total WBC (x10 $/ 1)$ & $2.1 \pm 0.3$ & $2.3 \pm 0.3$ & $2.0 \pm 0.3$ \\
Lymphocytes in blood (\%) & $97.2 \pm 0.8$ & $97.8 \pm 1.0$ & $97.5 \pm 0.9$ \\
Neutrophils in blood (\%) & $1.4 \pm 0.5$ & $1.2 \pm 0.5$ & $1.4 \pm 0.6$ \\
Monocytes in blood (\%) & $0.9 \pm 0.1$ & $0.6 \pm 0.1$ & $0.6 \pm 0.3$ \\
Eosinopils in blood (\%) & $0.6 \pm 0.3$ & $0.4 \pm 0.2$ & $0.5 \pm 0.3$ \\
\hline Total and differential WBC count: 4 h after elicitation of MAS model/ventilation therapy: \\
Total WBC (x10 $/ 1$ ) & $2.1 \pm 0.3$ & $1.6 \pm 0.4$ & $1.3 \pm 0.3$ \\
Lymphocytes in blood (\%) & $97.2 \pm 0.8$ & $77.7 \pm 3.5^{* * *}$ & $69.0 \pm 3.3^{* * *}$ \\
Neutrophils in blood (\%) & $1.8 \pm 0.8$ & $20.7 \pm 3.7^{* * *}$ & $29.1 \pm 3.1^{* * *}$ \\
Monocytes in blood (\%) & $0.9 \pm 0.1$ & $1.0 \pm 0.3$ & $1.5 \pm 0.2$ \\
Eosinopils in blood (\%) & $0.3 \pm 0.1$ & $0.4 \pm 0.1$ & $0.4 \pm 0.2$ \\
\hline
\end{tabular}

For between-group comparisons: ${ }^{*} \mathrm{P}<0.05$, ${ }^{*} \mathrm{P}<0.01,{ }^{*} * \mathrm{P}<0.001$ for Aura or SLE groups vs. Contr group, $\mathrm{P}>0.05$ for Aura vs. SLE groups. Data are expressed as means \pm SEM

the differences for lymphocytes $(\mathrm{P}=0.054)$ and neutrophils $(\mathrm{P}=0.068)$ were borderly nonsignificant (Tab. 2).

In both ventilated groups with MAS (Aura and SLE), higher concentrations of pro-inflammatory cytokines in the lung tissue and in the blood plasma were detected than in the healthy controls (all $\mathrm{P}<0.001$ vs. Contr, Figs. 1 and 2).

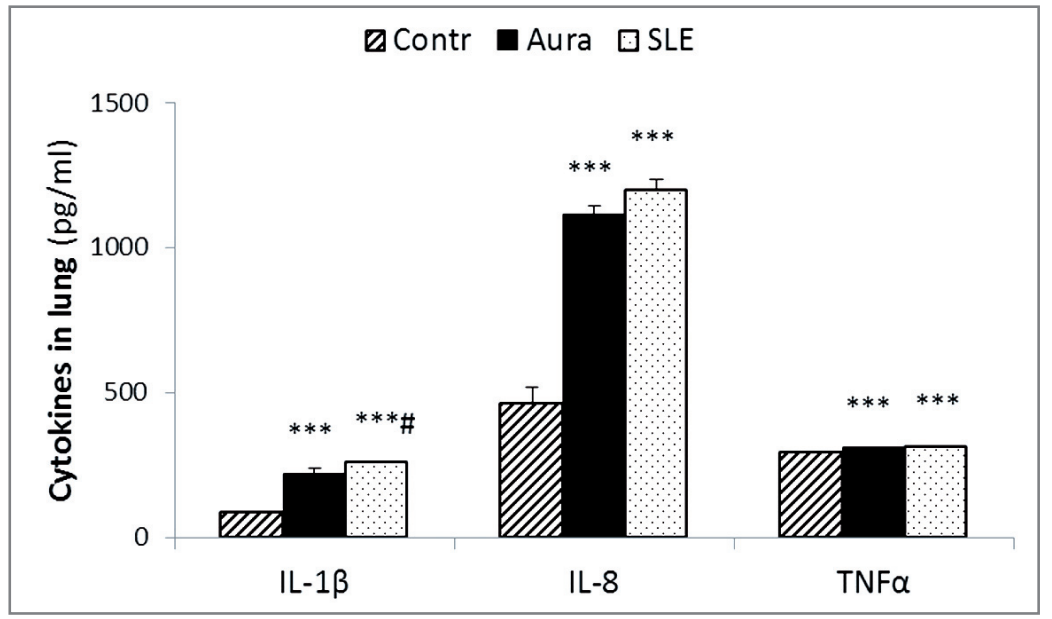

Fig. 1. Concentrations of IL- $1 \beta$, IL- 8 and TNF $\alpha$ in the lung tissue in the healthy controls (Contr group) and in the animals with MAS ventilated with ventilator Aura V (Aura group) or ventilator SLE5000 (SLE group).

For between-group comparisons: ${ }^{* *} \mathrm{P}<0.001$ for Aura or SLE groups vs. Contr group, ${ }^{\#} \mathrm{P}<0.05$ for Aura vs. SLE groups. Data are expressed as means \pm SEM. 
Levels of lung and plasma cytokines in the Aura and SLE groups were nearly comparable. The only significant difference between the ventilated groups was found for slightly higher IL-1 $\beta$ in the lung $(\mathrm{P}=0.026)$ and a borderly non-significant increase in $\mathrm{TNF}_{\alpha}(\mathrm{P}=0.055)$ in the SLE-ventilated animals (Figs. 1 and 2).

\section{DISCUSSION}

In severe MAS, artificial ventilation in the form of small-volume CMV with an appropriate PEEP is often required. In this study, the short-term effects of the small-volume CMV performed by two neonatal ventilators: Aura V (Chirana Stara Tura a.s., Slovakia) and SLE5000 (SLE Ltd., UK) on the lung functions of rabbits with experimentally-induced MAS were evaluated. Both ventilators were able to supply a sufficient gas exchange in the meconium-injured animals with a slightly better results for the Aura group early after elicitation of MAS model, while at the end of experiment there were no between-group differences in the respiratory parameters or blood gases. Analyzing the impact of both ventilators on the lung tissue, we found similar values of the wet-dry lung weight ratio, a marker of lung edema formation, and slightly lower levels of several pro-inflammatory cytokines in the Aura group, with an only significant difference for IL-1 $\beta$ in the lung tissue.

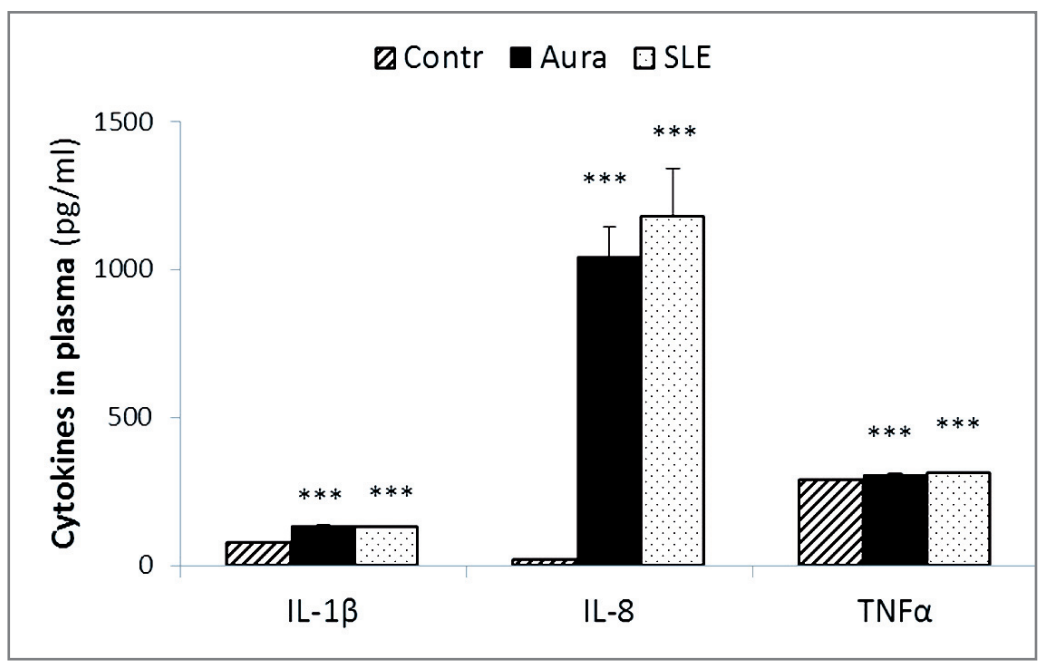

Fig. 2. Concentrations of IL- $1 \beta$, IL- 8 and $\mathrm{TNF}_{\alpha}$ in the blood plasma in healthy controls (Contr group) and in animals with MAS ventilated with ventilator Aura V (Aura group) or ventilator SLE5000 (SLE group).

For between-group comparisons: * $\mathrm{P}<0.05,{ }^{*} * * \mathrm{P}<0.001$ for Aura or SLE groups vs. Contr group, $\mathrm{P}>0.05$ for Aura vs. SLE groups. Data are expressed as means \pm SEM.

Spontaneously aspirated meconium in the newborns or experimentally-instilled meconium in the laboratory animals can trigger pathological changes in the lungs wery early. According to the animal species and a design of experiment, various meconium concentrations and dose volumes can be used. In our study, instillation of the meconium suspension with a concentration of $25 \mathrm{mg} / \mathrm{ml}$ and a dose of $4 \mathrm{ml} / \mathrm{kg}$ resulted in a decrease of the lung compliance of about $45 \%$ of the initial value, in a deterioration of the gas exchange, and significant inflammatory changes. This finding is in agreement with a common view that the meconium concentration of $25 \mathrm{mg} / \mathrm{ml}$ representing about $10 \%$ of the original meconium concentration creates a model of MAS with an accentuated alveolar component of the syndrome with predominant surfactant dysfunction and inflammation. In the rabbits, higher concentrations of meconium (20 or $25 \%$ of original concentration) suspended in the lower volume (e.g., $3 \mathrm{ml} / \mathrm{kg}$ ) could be also used, while 
that model generates an accentuation of the airway obstruction (9). However, for the purpose of our study the meconium concentration of $25 \mathrm{mg} / \mathrm{ml}$ appeared to be more suitable.

In our experiment, within several minutes after meconium instillation, the hypoxemia and hypercapnia occured, followed by acidosis. This situation needed to be solved by increased ventilatory pressures, as demonstrated by an increased value of MAP from initial value of $0.75 \mathrm{kPa}$ before meconium instillation to $1.1 \mathrm{kPa}$ after meconium instillation to supply an acceptable gas exchange in the meconium-instilled animals. The respiratory parameters worsened with a transport of meconium distally. Due to exposure to meconium, the lung compliance decreases and components of meconium trigger inflammatory and toxic changes in the lung parenchyma, impair the structure and function of the lung surfactant and influence the pulmonary circulation (9-13). In our study, we could observe a gradual worsening in the lung functions with time. Similar changes in the respiratory parameters, lung compliance, and blood gases were also found by other authors (14-18) and were previously also published by us (19-23). Deleterious effect of meconium on the lung tissue in this study was confirmed also by an increased migration of polymorphonuclears, particularly neutrophils into the lung, an increased production of pro-inflammatory substances and a generation of the lung edema. In agreement with our results, higher production of the pro-inflammatory cytokines and formation of lung edema in animals with MAS were demonstrated by other authors $(18,24,25)$, as well.

Of course, we are aware of some limitations of this study. Meconium suspension was instilled into the trachea of young, but not neonatal rabbits. Although the use of neonatal animals is of big advantage, as such models simulate the meconium aspiration on the background of postnatal changes of the lungs from a liquid-filled to an air-filled organ, due to technical and ethical difficulties associated with this procedure several days up to several weeks-old animals are often used. On the other hand, utilization of several weeks-old or adult piglets or rabbits can be advantageous, if different modes of the artificial ventilation are performed or treatments are delivered intratracheally, because young piglets and rabbits have similar size of the airways and similar body weights to those in the neonates. Other limiting factors are the inter-species differences in the immune responses and the differences related to a different dynamics of artificial meconium instillation vs. spontaneous aspiration by a neonate. Taking the limitations into account, the animal models are essential for understanding the pathophysiology of MAS and provide opportunity to search for novel therapeutical strategies.

During the period of observation ( $4 \mathrm{~h}$ ) after the elicitation of the model of MAS, the newly developed neonatal version of ventilator Aura $\mathrm{V}$ has provided a fully comparable efficacy to the ventilator SLE5000 in the gas exchange and potentially adverse impacts to the lung tissue. Even there was a trend for better gas exchange early after elicitation of MAS model and lower levels of some pro-inflammatory cytokines in the Aura group compared to the SLE group. However, because there were no significant differences in the blood gases and respiratory parameters at the end of experiment, we can consider the above mentioned differences to be not so convincing that they have any clinical importance.

Concluding, the ventilator Aura V is suitable for ventilation of the animals with meconiuminduced acute lung injury. It can be assumed that the ventilator Aura V could be of benefit also for ventilation of the neonatal patients suffering from MAS, but its efficacy must be further evaluated.

\section{REFERENCES}

1. van Ierland Y, de Beaufort AJ. Why does meconium cause meconium aspiration syndrome? Current concepts of MAS pathophysiology. Early Hum Dev 2009; 85 (10): 617-20.

2. Swarnam K, Soraisham AS, Sivanandan S. Advances in the management of meconium aspiration syndrome. Int J Pediatr 2012; 2012: 359571.

3. Mokra D, Mokry J. Meconium Aspiration Syndrome: From Pathomechanisms to Treatment. New York: Nova Science Publishers Inc.; 2010.

4. Singh BS, Clark RH, Powers RJ, Spitzer AR. Meconium aspiration syndrome remains a significant problem in the NICU: outcomes and treatment patterns in term neonates admitted for intensive care during a ten-year period. J Perinatol 2009; 29 (7): 497-503. 
5. Dargaville PA. Respiratory support in meconium aspiration syndrome: a practical guide. Int J Pediatr 2012; 2012: 965159.

6. Chowdhury O, Greenough A. Neonatal ventilatory techniques - which are best for infants born at term? Arch Med Sci 2011; 7 (3): 381-7.

7. Tomcikova L, Mokra D, Pistekova H, Kosutova P, Petraskova M, Javorka K, Jurcek M, Istona P, Calkovska A. Ventilator „Chirana Aura V“ in two models of neonatal acute lung injury - a pilot study. Acta Med Mart 2014; 14 (1): 20-26.

8. Lowry OH, Rosebrough NJ, Farr AL, Randall RJ. Protein measurement with the Folin phenol reagent. J Biol Chem 1951; 193 (1):265-75.

9. Davey AM, Becker JD, Davis JM. Meconium aspiration syndrome: physiological and inflammatory changes in a newborn piglet model. Pediatr Pulmonol 1993; 16 (2): 101-8.

10. Tyler DC, Murphy J, Cheney FW. Mechanical and chemical damage to lung tissue caused by meconium aspiration. Pediatrics 1978; 62 (4): 454-9.

11. Tran N, Lowe C, Sivieri EM, Shaffer TH. Sequential effects of acute meconium obstruction on pulmonary function. Pediatr Res 1980; 14 (1): 34-8.

12. Moses D, Holm BA, Spitale P, Liu MY, Enhorning G. Inhibition of pulmonary surfactant function by meconium. Am J Obstet Gynecol 1991; 164 (2): 477-81.

13. Kuo C, Chen J. Effect of meconium aspiration on plasma endothelin-1 level and pulmonary hemodynamics in a piglet model. Biol Neonate 1999; 76 (4): 228-34.

14. Sun B, Herting E, Curstedt T, Robertson B. Exogenous surfactant improves lung compliance and oxygenation in adult rats with meconium aspiration. J Appl Physiol (1985) 1994; 77 (4): 1961-71.

15. Hachey WE, Eyal FG, Curtet-Eyal NL, Kellum FE. High-frequency oscillatory ventilation versus conventional ventilation in a piglet model of early meconium aspiration. Crit Care Med 1998; 26 (3): 556-61.

16. Hummler HD, Thome U, Schulze A, Schnabel R, Pohlandt F, Franz AR. Spontaneous breathing during partial liquid ventilation in animals with meconium aspiration. Pediatr Res 2001; 49 (4): 572-80.

17. Robinson TW, Roberts AM. Effects of exogenous surfactant on gas exchange and compliance in rabbits after meconium aspiration. Pediatr Pulmonol 2002; 33 (2): 117-23.

18. Li AM, Zhang LN, Li WZ. Amelioration of meconium-induced acute lung injury by parecoxib in a rabbit model. Int J Clin Exp Med 2015; 8 (5): 6804-12.

19. Mokra D, Calkovska A, Drgova A, Javorka M, Javorka K. Treatment of experimental meconium aspiration syndrome with surfactant lung lavage and conventional vs. asymmetric high-frequency jet ventilation. Pediatr Pulmonol 2004; 38 (4): 285-91.

20. Mokry J, Mokra D, Antosova M, Bulikova J, Calkovska A, Nosalova G. Dexamethasone alleviates meconium-induced airway hyperresponsiveness and lung inflammation in rabbits. Pediatr Pulmonol 2006; 41 (1): 55-60.

21. Mokra D, Mokry J, Drgova A, Petraskova M, Bulikova J, Calkovska A. Intratracheally administered corticosteroids improve lung function in meconium-instilled rabbits. J Physiol Pharmacol 2007; 58 Suppl 5 (Pt 1): 389-98.

22. Mikolka P, Mokrá D, Kopincová J, Tomčíková-Mikušiaková L, Čalkovská A. Budesonide added to modified porcine surfactant Curosurf may additionally improve the lung functions in meconium aspiration syndrome. Physiol Res 2013; 62 (Suppl 1): S191-200.

23. Mikolka P, Kopincová J, Košútová P, Čierny D, Čalkovská A, Mokrá D. Lung inflammatory and oxidative alterations after exogenous surfactant therapy fortified with budesonide in rabbit model of meconium aspiration syndrome. Physiol Res 2016; 65 (Suppl 5): S653-62.

24. Zagariya A, Bhat R, Navale S, Chari G, Vidyasagar D. Inhibition of meconium-induced cytokine expression and cell apoptosis by pretreatment with captopril. Pediatrics 2006; 117 (5): 1722-7.

25. Silvera FE, Blasina MF, Vaamonde L, Tellechea S, Godoy C, Zabala S, Mañana G, Martell M, Olivera W. Sildenafil prevents the increase of extravascular lung water and pulmonary hypertension after meconium aspiration in newborn piglets. Braz J Med Biol Res 2011; 44 (8): 778-85.

Acknowledgements: Authors thank D. Kuliskova, Z. Remisova, M. Petraskova, and M. Hutko for technical assistance. This work was supported by the project „Biomedical Center Martin“, ITMS code: 26220220187, the project is co-financed from EU sources; and by projects APVV-15-0075 and APVV-0435-11, and VEGA $1 / 0305 / 14$.

Received: December,15,2016

Accepted: December,28,2016 